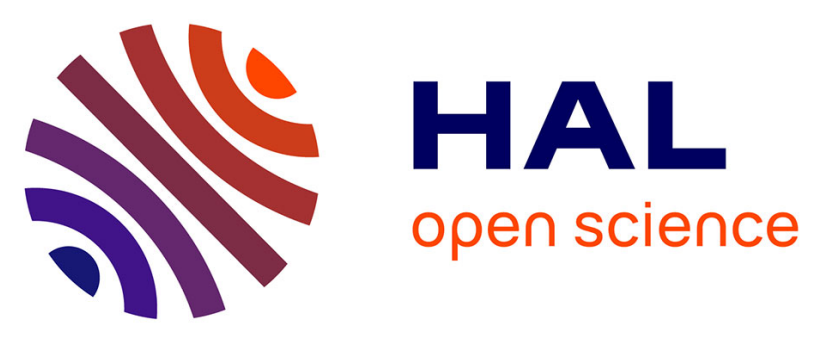

\title{
Performance evaluation of active sub-Terahertz systems in Degraded Visual Environments.
}

Romain Ceolato, Bernard Tanguy, Christian Martin, Thierry Huet, Patrick

Chervet, Gérard Durand, Nicolas Riviere, Patrick Hespel, Nina Diakonova, Dmitry But, et al.

\section{To cite this version:}

Romain Ceolato, Bernard Tanguy, Christian Martin, Thierry Huet, Patrick Chervet, et al.. Performance evaluation of active sub-Terahertz systems in Degraded Visual Environments.. Degraded Visual Environments: Enhanced, Synthetic, and External Vision Solutions 2016, 9839, 10 p., 2016, 10.1117/12.2223939 . hal-01464825

\section{HAL Id: hal-01464825 \\ https://hal.science/hal-01464825}

Submitted on 22 Nov 2021

HAL is a multi-disciplinary open access archive for the deposit and dissemination of scientific research documents, whether they are published or not. The documents may come from teaching and research institutions in France or abroad, or from public or private research centers.
L'archive ouverte pluridisciplinaire HAL, est destinée au dépôt et à la diffusion de documents scientifiques de niveau recherche, publiés ou non, émanant des établissements d'enseignement et de recherche français ou étrangers, des laboratoires publics ou privés.

\section{(ㄷ)(1) $\$$}

Distributed under a Creative Commons Attribution - NonCommerciall 4.0 International 


\title{
Performance evaluation of active sub-Terahertz systems in Degraded Visual Environments
}

\author{
Romain Ceolato*a ${ }^{\mathrm{a}}$, Bernard Tanguy ${ }^{\mathrm{a}}$, Christian Martin ${ }^{\mathrm{a}}$, Thierry Huet ${ }^{\mathrm{a}}$, Patrick Chervet ${ }^{\mathrm{a}}$, \\ Gerard Durand ${ }^{\mathrm{a}}$, Nicolas Riviere ${ }^{\mathrm{a}}$, and Laurent Hespel ${ }^{\mathrm{a}}$ \\ Nina Diakonova ${ }^{\mathrm{b}}$, Dmitry But ${ }^{\mathrm{b}}$, and Wojciech Knap ${ }^{\mathrm{b}}$ \\ Jerome Meilhan $^{\mathrm{c}}$, Baptiste Delplanque ${ }^{\mathrm{c}}$, Jonathan $\mathrm{Oden}^{\mathrm{c}}$, and Francois Simoens ${ }^{\mathrm{c}}$ \\ aNERA, The French Aerospace Lab, 2 avenue Edouard Belin, 31055 Toulouse Cedex, France; \\ ${ }^{\mathrm{b}}$ CNRS Laboratoire Charles Coulomb UMR 522, Université Montpellier, \\ 2 Place Eugene Bataillon, 34905 Montpellier, France; \\ ${ }^{c}$ CEA Leti-MINATEC campus, 17 rue des Martyrs, 38054 Grenoble Cedex 9, France.
}

\begin{abstract}
This paper addresses the problem of critical operations in Degraded Visual Environment (DVE). DVE usually refer when the perception of a pilot is degraded by environmental factors, including the presence of obscurants from bad weather (e.g. fog, rain, snow) or accidental events (e.g. brownout, whiteout, smoke). Critical operations in DVE are a growing field of research as it is a cause of numerous fatal accidents for operational forces. Due to the lack of efficient sources and sensors in the Terahertz (THz) region, this domain has remained an unexplored part of the electromagnetic spectrum. Recently, the potential use of sub-Terahertz waves has been proposed to see through dense clouds of obscurants (e.g. sand, smoke) in DVE conditions. In order to conduct a performance evaluation of sub-Terahertz systems, several sub-terahertz systems (e.g. bolometer-array cameras, liquid helium cooled bolometers) were operated in artificial controlled DVE conditions at ONERA facilities. The purpose of this paper is to report field experiments results in controlled DVE conditions: attenuation measurements from $400 \mathrm{GHz}$ to $700 \mathrm{GHz}$ with a performance evaluation of different sub-Terahertz systems are presented.
\end{abstract}

Keywords: Terahertz, Brownout, DVE, Obscurants, See-through systems.

*Romain.Ceolato@onera.fr; phone +33562252617 ; www.onera.fr. 


\section{INTRODUCTION}

\subsection{Problem of DVE}

The problem of critical operations such as take-off and landing of helicopters or unmanned vehicles in Degraded Visual Environment (DVE) is addressed in this research work. During these critical operations, one particularly challenging problem is the requirement to identify targets to operate in DVE in order to improve situational awareness for pilots. These targets are generally used as visual references and may be obscured by man-made or natural obscurants, including bad weather (e.g. fog, haze, rain, snow, dust) or accidental events (e.g. brownout, whiteout, smoke).
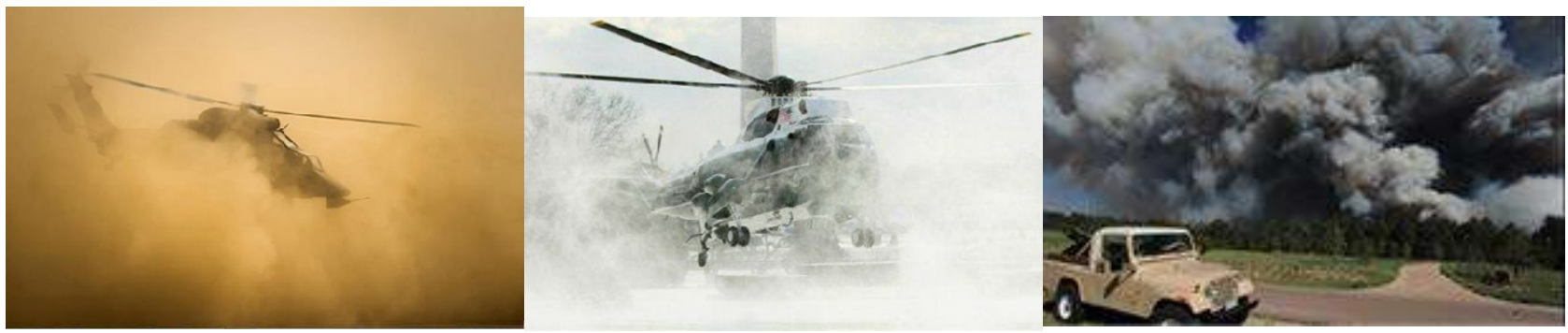

Figure 1: Examples of DVE conditions.

Several military aircrafts were lost in operational missions due to helicopter landing and take-off operations in desert areas [1]. The phenomenon of "brownout" is an operational problem for most types of rotorcraft, especially those operating in dry and arid climates [2-4]. The pilot loses all visual references, and this can induce a dangerous sideward or rearward drift during takeoff or touchdown, which most aircraft cannot safely handle [5]. The shape of the brownout cloud also seems to be highly influenced by the flight path characteristics of the helicopter and rotor configuration [6]. A typical brownout cloud containing billions of sediment particles ranging in different sizes from can be influenced by a wide range of factors [7].

\subsection{Propagation of $\mathrm{THz}$ waves}

Different technologies have been proposed to sense through obscurants such as Millimeter-waves (MMW) or laser imaging systems [8]. In recent decades, the development of terahertz technologies has been accompanied by a growing interest in $\mathrm{THz}$ imaging techniques for a variety of military and civilian applications $[9,10]$. This electromagnetic domain resides between microwaves and infrared $(\sim 0.08 \mathrm{THz} \sim 10 \mathrm{THz})$. Information obtained with $\mathrm{THz}$ spectroscopy for materials are unique characteristics like fingerprints to identify them. Another advantageous property of $\mathrm{THz}$ waves is their capability for penetrating many non-conducting materials. Therefore, THz radiation can be used in various fields such as security for imaging concealed weapons carried by people or imaging in degraded visual environments.

In the seventies or eighties, terahertz technology was not mature for the receiver sensibility but now this limitation is overcome, to increase large development of passive millimeter wave focal plane array camera. Technologies based on terahertz $(\mathrm{THz})$ waves have emerged with attractive applications in defense, security, medicine, material science, or astronomy. They are relatively insensitive to atmospheric conditions in many frequency bands and are independent of the solar illumination. Generally, the choice of frequencies is restricted where atmospheric absorption gases are smaller: 35 $\mathrm{GHz}, 94 \mathrm{GHz}, 140 \mathrm{GHz}$, and $220 \mathrm{GHz}$ [11]. Optical properties may induce absorption, scattering and emission of terahertz radiations described by the radiative transfer equation. Previous work reported the potential use of sub- $\mathrm{THz}$ radiations to see through dense clouds of obscurants (e.g. sand, dust) in DVE conditions [12]. This paper reports an experimental evaluation of the obscurant penetrating capability of sub- $\mathrm{THz}$ waves from $400 \mathrm{GHz}$ to $700 \mathrm{GHz}$. 


\section{LABORATORY CARACTERISATION}

\subsection{Description of the optical system}

In clear atmosphere, several propagation windows are present in the sub- $\mathrm{THz}$ frequency range. This bands are of particular interest for stand-off imaging that can be achieved either by passive imaging system [13] that require cryogenic detectors or active imaging scheme [14] by illumination of the target and detection with uncooled devices. Depending on the application one will favor higher frequencies windows in order to improve imaging resolution, at the cost of a lower screening range due to increased attenuation of residual water vapor with frequency. In DVE choice of the imaging frequency will be steered by diffusion of the obscurant particles. Useful bands will tend to lower frequencies for large particle size and a trade-off has to be made. Experimental data on effective transmission through typical obscurant encountered in DVE is mandatory in order to feed the conception of an imaging system and a dedicated optical setup has been developed to carry out transmission measurement in various controlled DVE conditions.
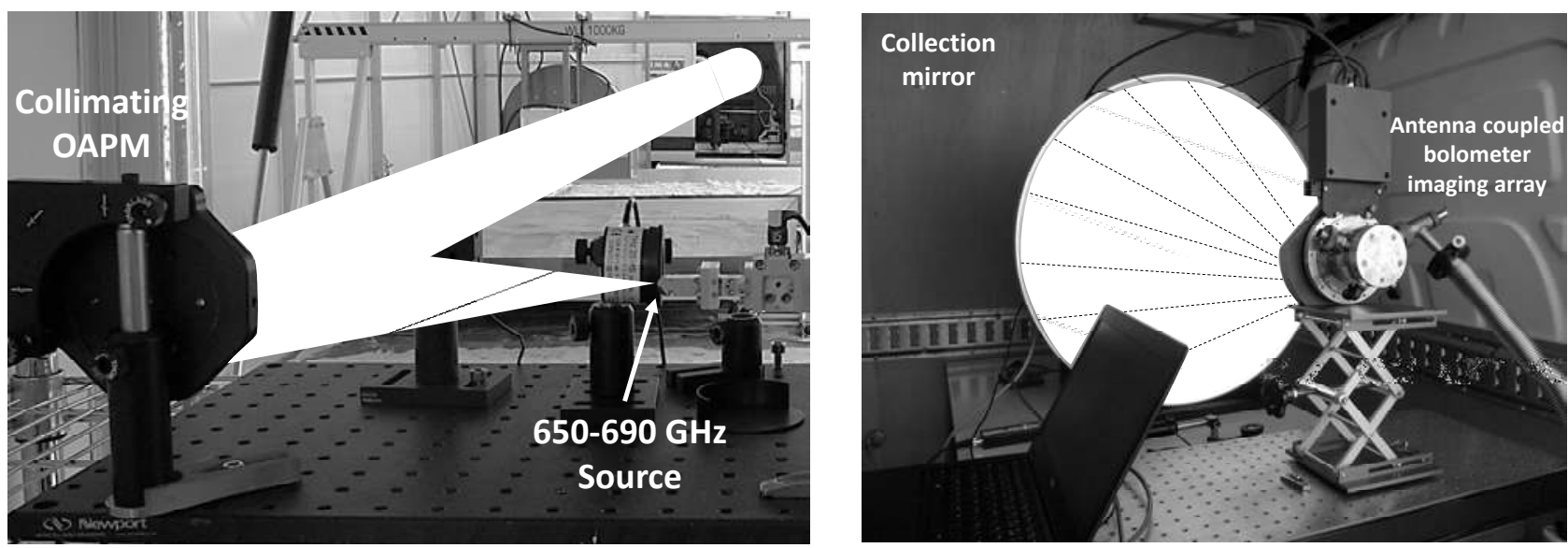

Figure 2: Optical setup for beam imaging in clear atmosphere condition with the antenna coupled bolometer camera

Validation of the setup has been performed by clear atmosphere imaging of the THz beam that is collimated towards the parabolic collection mirror. Real time imaging of the beam was delivered by an uncooled bolometer array developed at CEA-LETI that allowed optimization of optical alignment for further measurements in DVE conditions. According to the camera sensitivity with respect to frequency, the $650-700 \mathrm{GHz}$ transmission window been selected for beam imaging in the best operational conditions. Beam was delivered by a tunable terahertz electronic source based on Schottky frequency multipliers from $\mathrm{VDI}^{\circledR}$. Typical output power of the source lies between 1.5 to $2 \mathrm{~mW}$ over the frequency range.

\subsection{Cameras caracterisation}

The uncooled camera consists in a 320x240 array of antenna-coupled bolometers with a $50 \mu \mathrm{m}$ pixel pitch. Pixel design has been optimized for optimal sensitivity in the 1 to $3 \mathrm{THz}$ range thanks to a cross polarized antenna structure backed by a quarter wavelength dielectric cavity [15]. This camera presents minimum detectable power (MDP) values of a few tens of $\mathrm{pW}$, depending on the frequency. At $2.4 \mathrm{THz}$, experimental characterizations of the camera operated in real time imaging conditions ( $25 \mathrm{~Hz}$ frame rate), resulted in measured MDP of $32 \mathrm{pW}$ and $80 \%$ absorption efficiency of the incident wave. Better MDP can be observed at the antenna resonances while this figure of merit degrades at lower frequencies that are out of the antenna frequency bandwidth. 


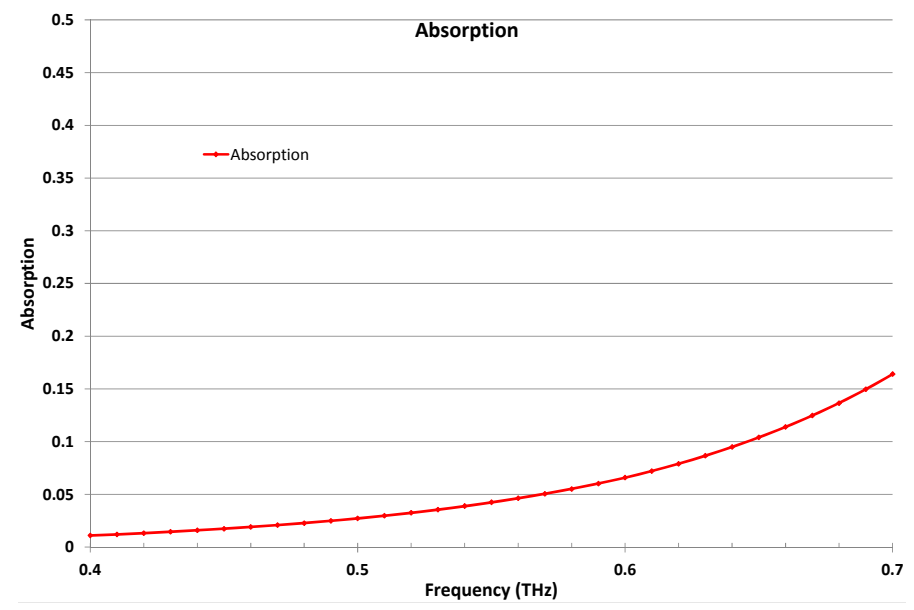

Figure 3: Simulated absorption the antenna coupled bolometer camera between 0.4 and $0.7 \mathrm{THz}$

The previous figure presents the simulated absorption of the antenna-coupled bolometer detectors in the $0.4-0.7 \mathrm{THz}$ frequency range. Below $0.5 \mathrm{THz}$, absorption of the impinging wave drops below $2 \%$ and sensitivity becomes too low for beam imaging with sufficient Signal to Noise Ratio (SNR). Towards higher frequencies, camera absorption increasing will lower the threshold detection while presence of a transmission window around $650 \mathrm{GHz}$ will improve the $\mathrm{THz}$ power impinging on the imager. Preliminary measurements of the camera performances in this band confirmed the simulated absorption that is in the order of a few \% with resulting responsivity is close to $1 \mathrm{MV} / \mathrm{W}$ between $650-700$ $\mathrm{GHz}$.

\section{FIELD EXPERIEMENTS}

\subsection{Artificial controlled DVE conditions}

An aerosol chamber was developed at ONERA, The French Aerospace Lab in order to evaluation performance of several EO/IR active and passive systems. Different aerosols or hydrometeors such as fog or rain are generated, monitored and controlled inside the chamber. Smoke is generated by burning oil. To evaluate the propagation of sub- $\mathrm{THz}$ wave through DVE such brownout conditions, an artificial brownout was generated with a vertical blower placed above different types of sand which have similar characteristics, in terms of particle size distribution and optical index, to several theaters of operations.

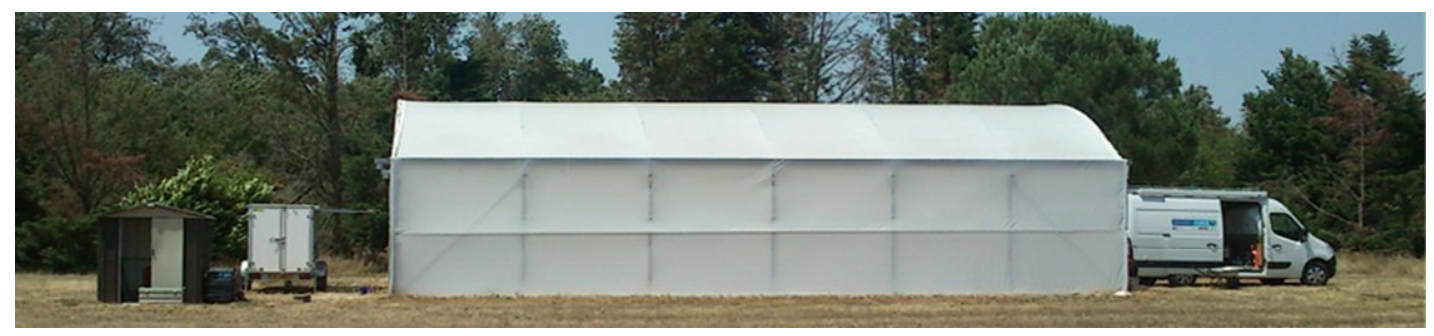

Figure 4: Overview of ONERA aerosol chamber. 


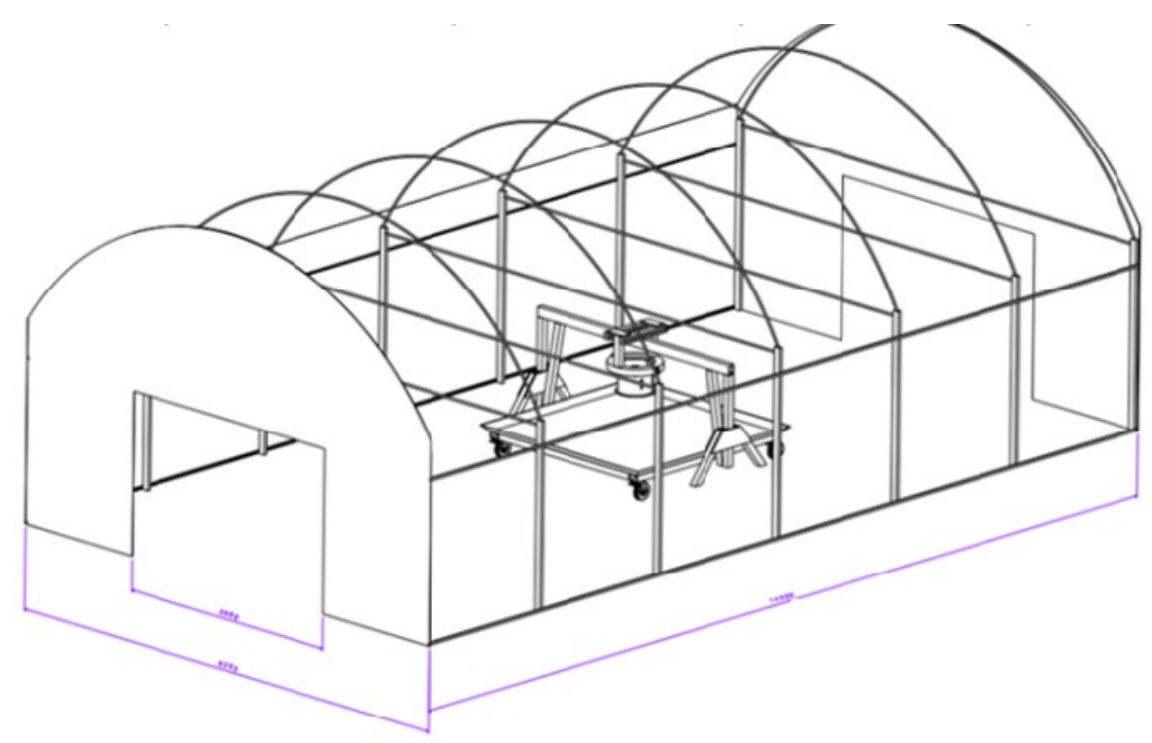

Figure 5. Overview of ONERA vertical blower for artificial brownout generation.

\subsection{Optical setup}

Amplification/Multiplication Chains (AMC) WR6.5AMC and WR10M-AMC with additional frequency multipliers, VDI, Inc were used to produce the sub- $\mathrm{THz}$ radiation. The AMC was fed with the $10 \mathrm{dBm}$ power radiofrequency signal from the functional generator.
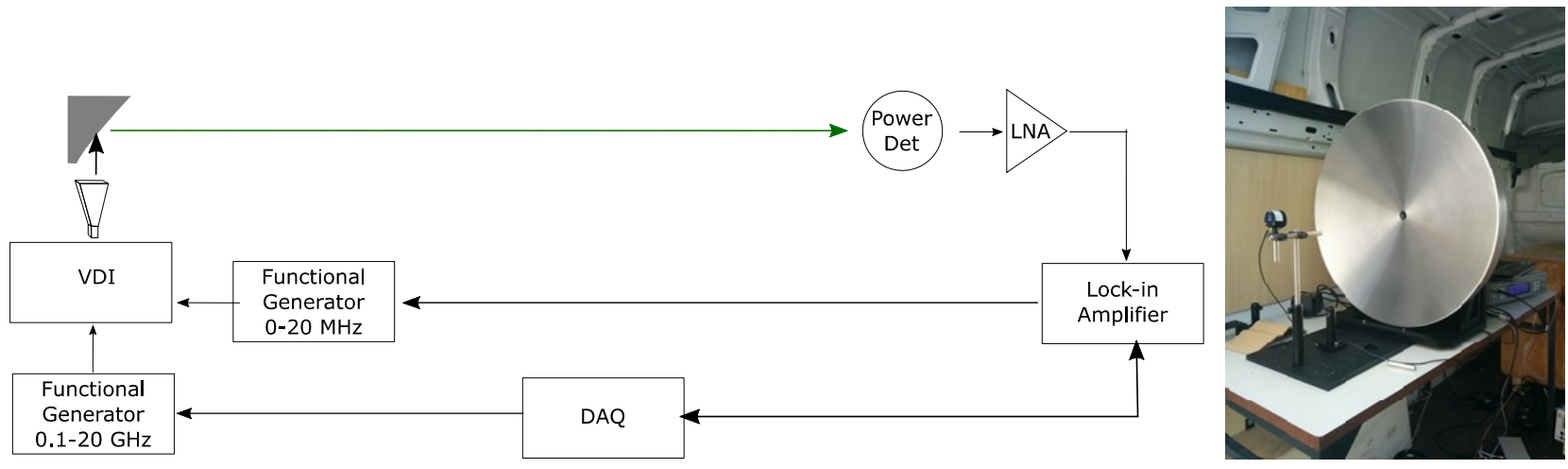

Figure 6: Optical setup for sub-THz wave attenuation measurements.

We studied atmospheric transmission under different conditions in following frequency ranges with typical output power of radiation: $110-170 \mathrm{GHz}(8 \mathrm{dBm}), 220-330 \mathrm{GHz}(-2 \mathrm{dBm}), 400-600 \mathrm{GHz}(-20 \mathrm{dBm}), 660-900 \mathrm{GHz}(-25 \mathrm{dBm})$. The $\mathrm{THz}$ radiation passed through the air space and was collected by the offset type parabolic antenna of $40 \mathrm{~cm}$ diameter at the distance of $20 \mathrm{~m}$. Antenna focused the radiation on the power detector; next, the detector output signal was filtered and amplified. For low frequency range we used pyroelectric detector with its own preamplifier, for high frequency range the more sensitive Si Bolometer cooled down to $4.2 \mathrm{~K}$ followed by the 5113 low noise amplifier was necessary. For signal detection we used a lock-in technique. The amplitude of the output THz radiation was modulated by a TTL signal of $79 \mathrm{~Hz}$ frequency from the functional generator. The frequency sweep and data acquisition were controlled by a computer. 


\subsection{Camera results}

During experiment a trigger signal switches off the source emission periodically. It allows differential operation of the imager and ensures that delivered signal results only from the $\mathrm{THz}$ beam out of any low frequency drifts that can arise from temperature changes of the background.

Figure 7 shows the beam distribution at the focal point of the paraboloid mirror for 2 frequencies of the emitting source, respectively $670 \mathrm{GHz}$ for image a) and $655 \mathrm{GHz}$ for image b). Beam pattern is similar in both cases excepting for a broadening of the beam in the elevation plane of the optical setup at $655 \mathrm{GHz}$. The total signal integrated over the array is close to $170 \mathrm{~V}$ for the two frequencies and is consistent with the almost constant absorption coefficient within the transmission window. Considering the array responsivity the collected power is around $170 \mu \mathrm{W}$ corresponding to $10 \%$ of the power emitted by the source.
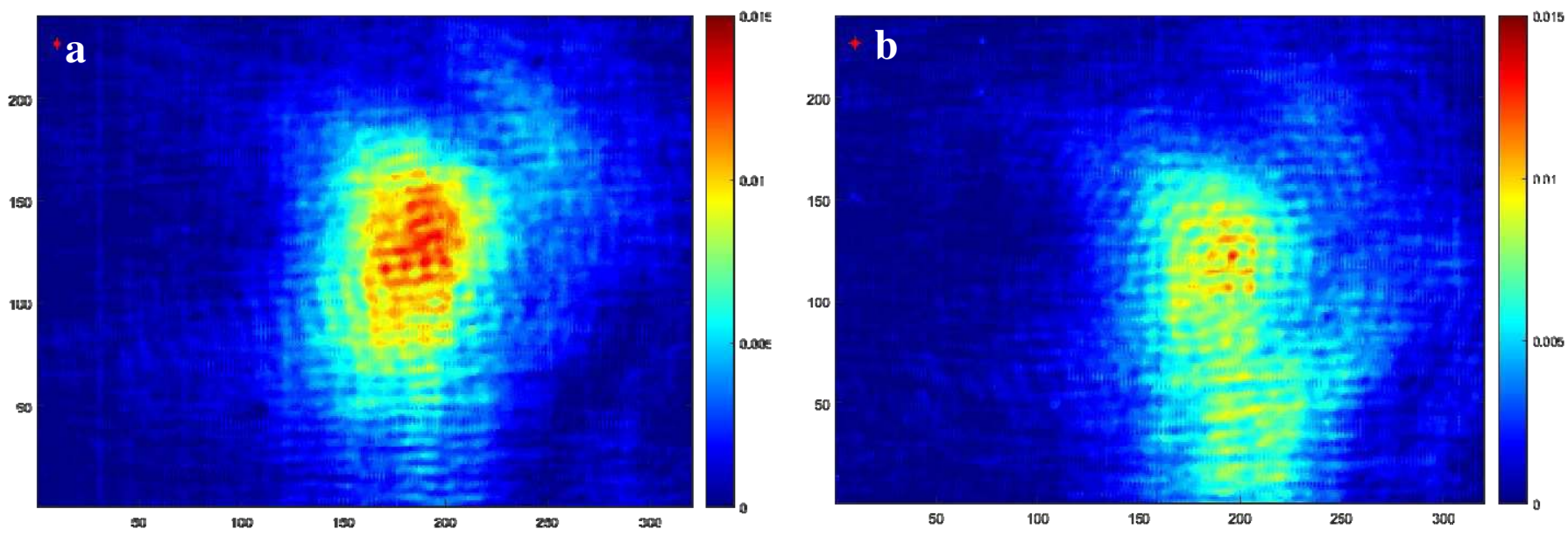

Figure 7: Beam images at $670 \mathrm{GHz}($ a) and $655 \mathrm{GHz}$ (b) for similar optical alignment

Central optical obstruction due to the camera can reduces the collected optical power and must be accounted in the losses from source to camera. In our case, size of the collimated beam impinging on the parabolic mirror is much lower than the collection area and is more prone to obstruction. In order to limit the impact of obstruction on collected power, incident beam has been tilted resulting in off-axis illumination of the parabolic mirror. Image of the beam is presented in Figure 8.

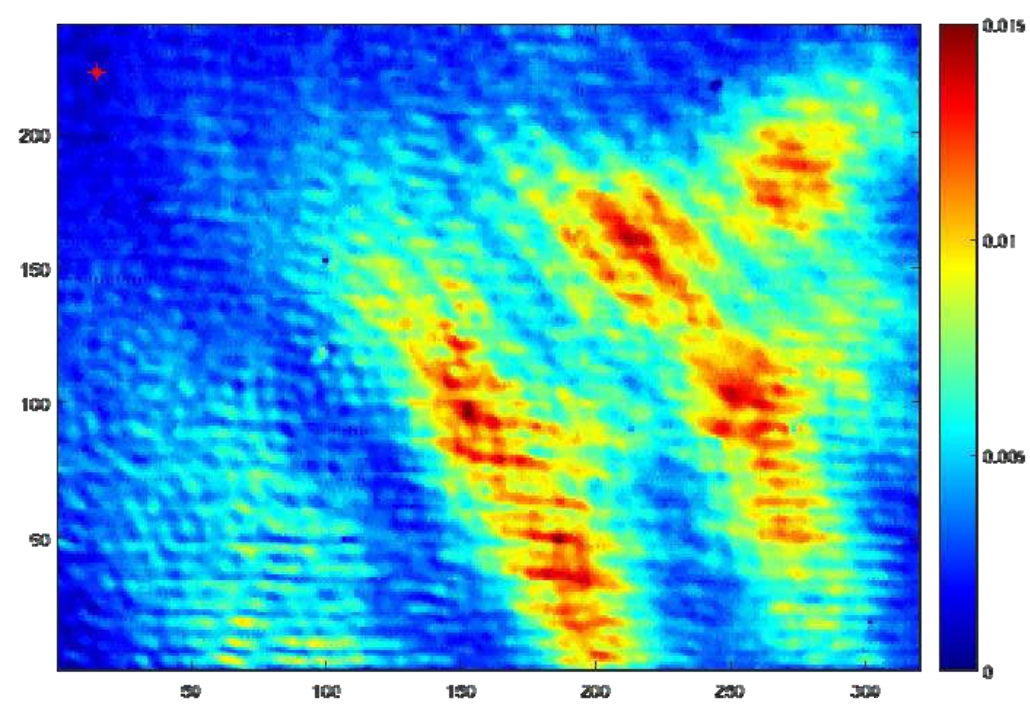

Figure 8: Beam images at $670 \mathrm{GHz}$ for off-axis illumination 
Strong coma due to off-axis incidence can be observed but the overall collected power increases. Estimated collected power is close to $412 \mu \mathrm{W}$ and reaches almost $25 \%$ of the source output power. Considering the probed relative humidity during experiment that is in the vicinity of $90 \%$, the power of the propagated beam on the collecting mirror is around $850 \mu \mathrm{W}$. This leads to half of the incident power collected on the focal plane array while the beam is larger than the $16 \mathrm{x}$ $12 \mathrm{~mm}^{2}$ area of the sensor.

\section{BROWNOUT PENETRATION PERFORMANCE}

In this section, brownout penetration performance was evaluated using different categories of sand, i.e. fine and coarse sand between 440 and $660 \mathrm{GHz}$.

\subsection{Coarse sand brownout penetration performance}

We report results of sub-THz wave penetration through a coarse sand brownout. The experimentation was carried out inside the climate chamber described above where an artificial brownout has been generated from coarse sand. The averaged visibility in clear atmosphere, brownout, and clear atmosphere + dust was measured at $20 \mathrm{~km}, 0.05 \mathrm{~km}$, and 1.0 $\mathrm{km}$. The ambient temperature was $289 \mathrm{~K}$, the relative humidity was $52 \%$ and the atmospheric pressure was $999 \mathrm{~Pa}$.

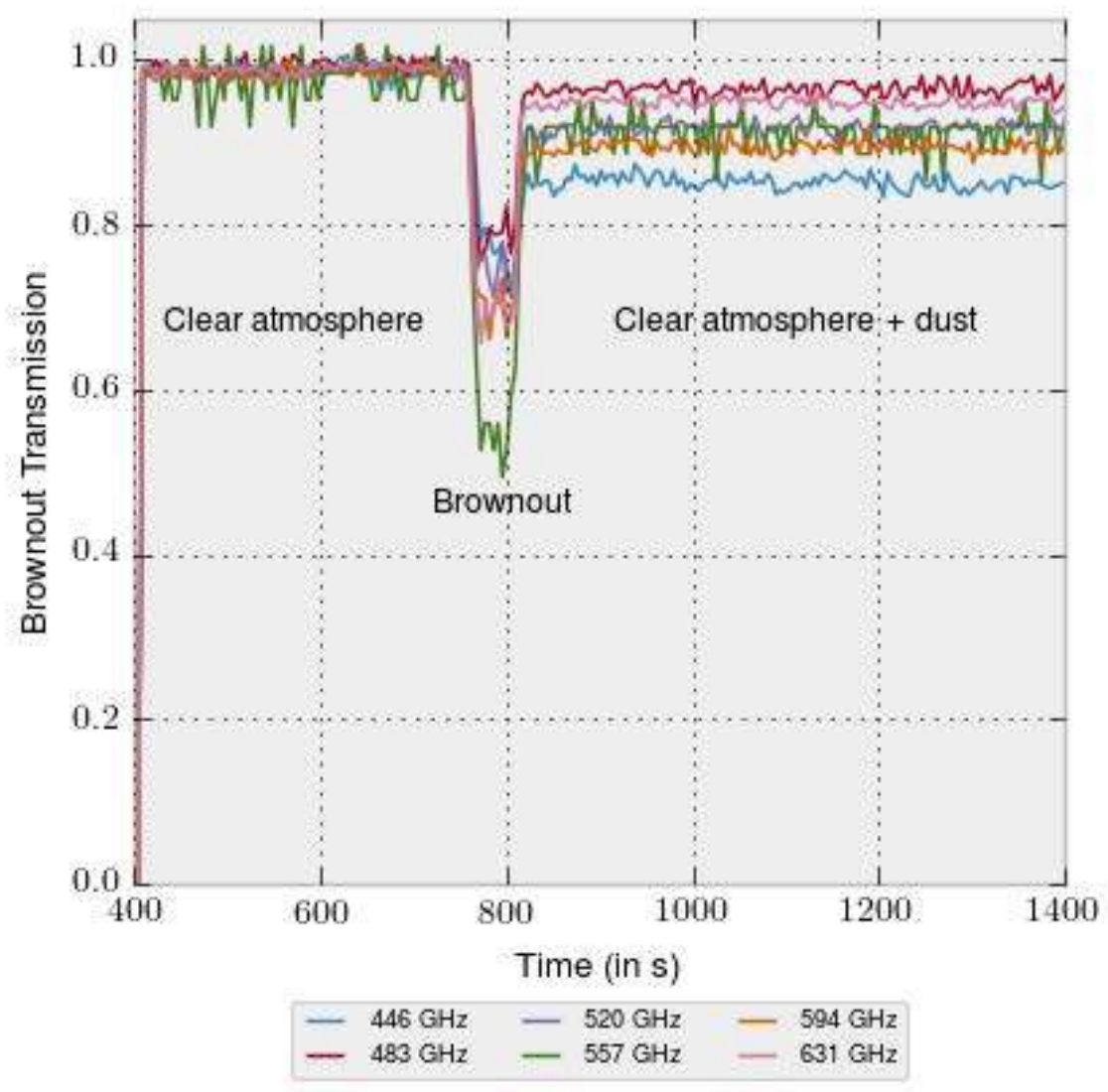

Figure 9: Coarse sand brownout transmission over a 15 m distance at $446 \mathrm{GHz}, 483 \mathrm{GHz}, 520 \mathrm{GHz}, 557 \mathrm{GHz}, 594$ GHz, and $631 \mathrm{GHz}$. 
One crucial concern of $\mathrm{THz}$ technologies is the attenuation of EM waves from source emitters to sensors. Atmospheric attenuation results from absorption and scattering by gas and aerosols constituting the atmosphere. Terahertz light is absorbed by atmospheric water vapor within small distances [10] but for a typical brownout extension, we aim at evaluating their penetration performance. Results from Figure 10 shows that sub-terahertz radiations are attenuated from $20 \%$ to $50 \%$ from 446 to $631 \mathrm{GHz}$. This attenuation is due to both scattering and absorption by sand particles composing the brownout. A maximum attenuation at $557 \mathrm{GHz}$ was reported where gaseous absorption is maximal. After the generation of brownout, we noticed that radiations remain attenuated from 5\% to 15\%, which can be explained by scattering of small dust particles inside the aerosol chamber.

\subsection{Fine sand brownout penetration performance}

We report results of sub-THz wave penetration through a fine sand brownout. The experimentation was carried out inside the climate chamber described above where an artificial brownout has been generated from coarse sand. The averaged visibility in clear atmosphere, brownout, and clear atmosphere + dust was measured at $20 \mathrm{~km}, 0.05 \mathrm{~km}$, and 3.0 $\mathrm{km}$. The ambient temperature was $288 \mathrm{~K}$, the relative humidity was $55 \%$ and the atmospheric pressure was $999 \mathrm{~Pa}$.

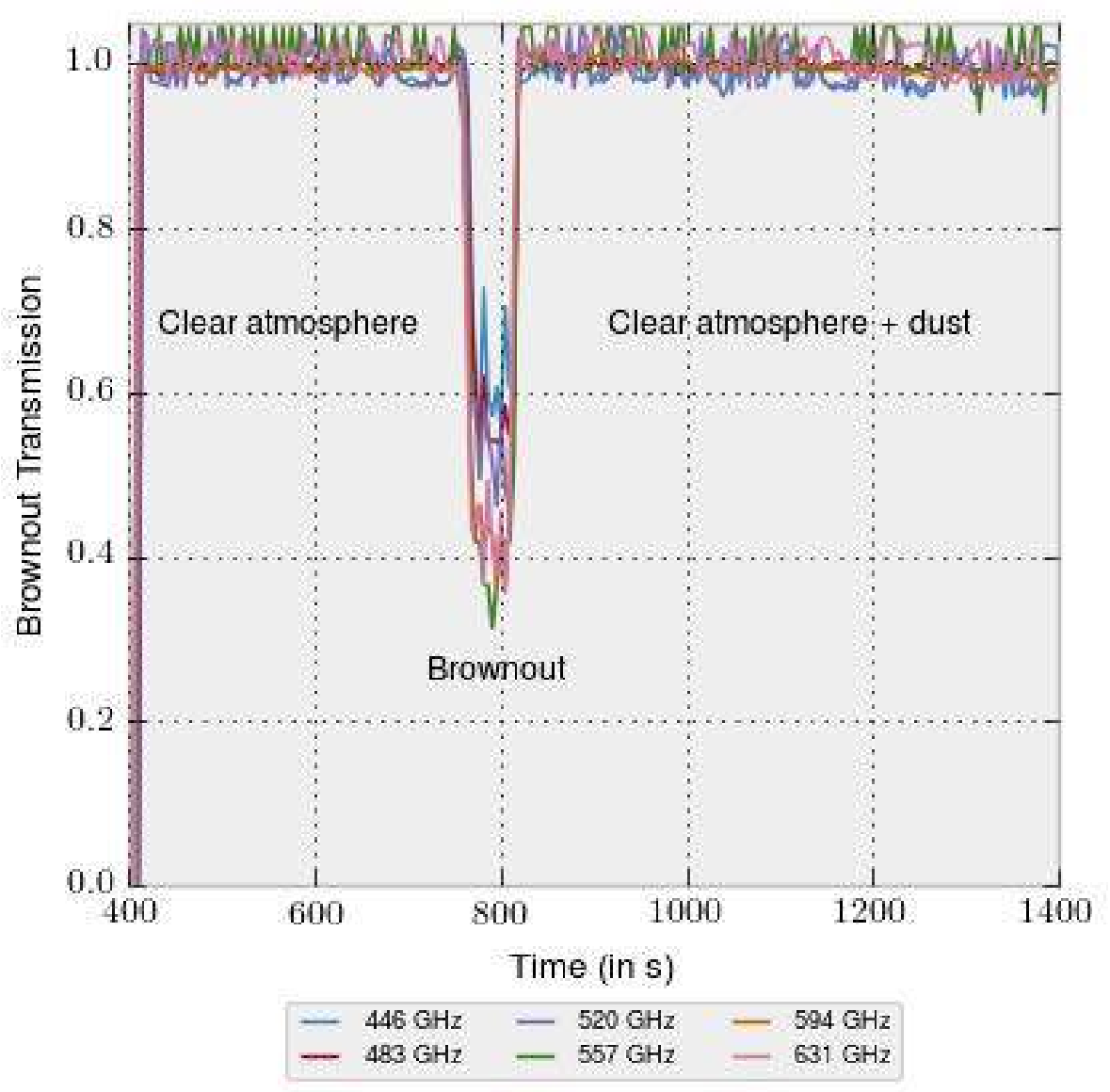

Figure 10: Fine sand brownout transmission over a 15 m distance at $446 \mathrm{GHz}, 483 \mathrm{GHz}, 520 \mathrm{GHz}, 557 \mathrm{GHz}$, $594 \mathrm{GHz}$, and $631 \mathrm{GHz}$. 
The sub-terahertz radiations are attenuated from $40 \%$ to $70 \%$ from 446 to $631 \mathrm{GHz}$. Similar to previous measurements for coarse sand brownout, the attenuation of the sub-terahertz radiations is governed by scattering from sand particles. We also report a maximum attenuation at $557 \mathrm{GHz}$ where gaseous absorption is maximal. For fine sand absorption, we report a stronger extinction compared to coarse sand brownout.

\section{CONCLUSION}

Our field experiments results encourage the potential use of imaging systems based on sub-Terahertz waves to see through dense clouds of obscurants (e.g. sand, smoke) in DVE conditions. A performance evaluation of sub-Terahertz systems, several sub-terahertz systems (e.g. bolometer-array cameras, liquid helium cooled bolometers) were operated from $400 \mathrm{GHz}$ to $700 \mathrm{GHz}$ in artificial controlled DVE conditions at ONERA facilities. For different types of sand (e.g. fine an coarse sand), direct measurements with active sub- $\mathrm{THz}$ sources from 446 to $631 \mathrm{GHz}$ show an attenuation of the radiations from $20 \%$ to $70 \%$ by the brownout cloud. A maximum attenuation at $557 \mathrm{GHz}$ was reported where gaseous absorption is maximal.

This attenuation seems to originate from both scattering and absorption by sand particles composing the brownout. In addition, the attenuation appears to be closely related to the sand composition, i.e. the particle size distribution and the complex optical index (both refractive index and absorption coefficient). These microphysical parameters may play a major role in the attenuation measurements and will be further investigated using dedicated simulation models.

\section{REFERENCES}

[1] A. Davis, The Use of Commercial Remote Sensing In Predicting Helicopter Brownout Conditions, Monterey : Naval Post-Graduate School, 2007.

[2] O. D.Wong, P. E. Tanner, Photogrammetric Measurements of an EH-60L Brownout Cloud, American Helicopter Society 66th Annual Forum and Technology Display; Phoenix, AZ; United States, 11-13 May, 2010.

[3] J. Milluzzo, J. G. Leishman, Assessment of Rotorcraft Brownout Severity in Terms of Rotor Design Parameters, Journal of the American Helicopter Society 55, 032009, 2010.

[4] J. K. Tritschler, M. Syal, R. Celi, J. G. Leishman, A Methodology for Rotorcraft Brownout Mitigation Using Rotor Design Optimization, 66th Annual Forum of the American Helicopter Society, Phoenix, AZ, May 10-13, 2010.

[5] S. Colby, Military Spin: Help With Brownouts, Rotor \& Wing, March 2005.

[6] S. Ghosh, M. Kohry, and R. Rajagopalan. "Rotor Configurational Effect on Rotorcraft Brownout",Proc. 28th Applied Aerodynamics Conference, 28 June -1 July 2010.

[7] M. Syal, B. Govindarajan, J. G. Leishman, Mesoscale Sediment Tracking Methodology to Analyze Brownout Cloud Developments, American Helicopter Society 66th Annual Forum, Phoenix, Arizona, 10-13 May 2010.

[8] STO-TR-SET-135 - High-Performance Passive/Active Radiometric MMW Imaging Using Thinned Arrays, Jan. 2015.

[9] F. C. De Lucia, THz Technology and Molecular Interactions, Final report, DAAD19-00-1-0109, 2010.

[10] S. R. Murrill, B. Redman, R. L. Espinolac, Advanced terahertz imaging system performance model for concealed weapon identification," Proc. SPIE, Vol. 6549, 654902, 2007.

[11] H. J. Liebe, MPM-An atmospheric millimeter-wave propagation model, Int. J. Infrared Milli, 10, 631-50, 1989.

[12] S. T. Fiorino, J. A. Deibel, P. M. Grice, M. H. Novak, J. Spinoza, L. Owens, S. Ganti, A technique to measure optical properties of brownout clouds for modeling terahertz propagation, Applied Optics, Vol. 51, No. 16, 3605-3613, 2012.

[13]E. Heinz, T. May, D. Born, G. Zieger, S. Anders, V. Zakosarenko, H.-G. Meyer, and C. Schäffel, Passive 350 GHz Video Imaging Systems for Security Applications, J Infrared Milli Terahz Waves, vol. 36, no. 10, pp. 879895, Jun. 2015.

[14] N. Oda, M. Sano, Kenichi Sonoda, H. Yoneyama, S. Kurashina, M. Miyoshi, T. Sasaki, I. Hosako, N. Sekine, T. Sudou, and S. Ohkubo, "Development of Terahertz focal plane arrays and handy camera," vol. 8012, p. 80121B-80121B-9, 2011.

[15]F. Simoens and J. Meilhan, "Terahertz real-time imaging uncooled array based on antenna- and cavity-coupled bolometers," Philosophical Transactions of the Royal Society of London A: Mathematical, Physical and Engineering Sciences, vol. 372, no. 2012, p. 20130111, Mar. 2014. 